\title{
Thin Film Contamination Effects on Laser-Induced Damage of Fused Silica Surfaces at $355 \mathrm{~nm}$
}

\author{
F. Y. Génin, A. M. Rubenchick, A. K. Burnham, \\ M. D. Feit, J. Yoshiyama, A. Fornier, \\ C. Cordillot, and D. Schirmann
}

This paper was prepared for submittal to the Third Annual International Conference on Solid State Lasers for Application (SSLA) to Inertial Confinement Fusion (ICF) Monterey, California June 7-12, 1998

July 28, 1998

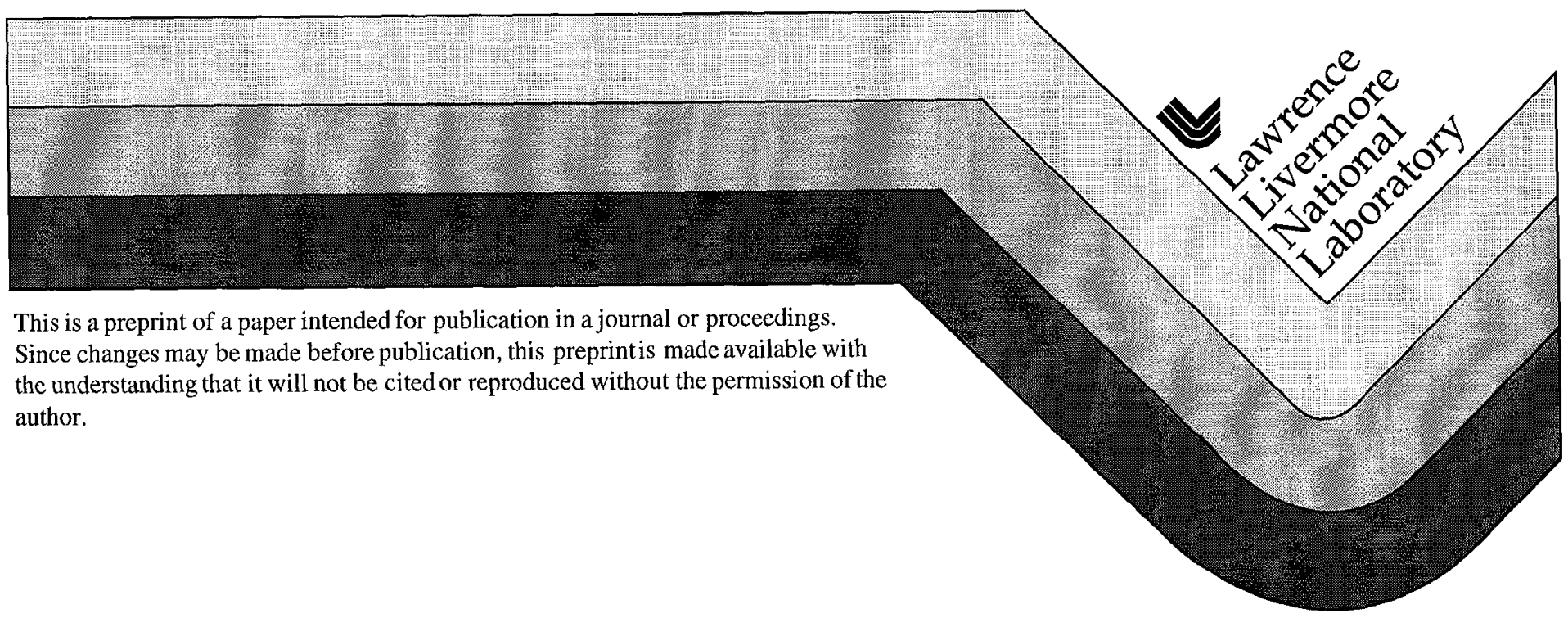


DISCLAIMER

This document was prepared as an account of work sponsored by an agency of the United States Government. Neither the United States Government nor the University of California nor any of their employees, makes any warranty, express or implied, or assumes any legal liability or responsibility for the accuracy, completeness, or usefulness of any information, apparatus, product, or process disclosed, or represents that its use would not infringe privately owned rights. Reference herein to any specific commercial product, process, or service by trade name, trademark, manufacturer, or otherwise, does not necessarily constitute or imply its endorsement, recommendation, or favoring by the United States Government or the Universily of California. The views and opinions of authors expressed herein do not necessarily state or reflect those of the United States Government or the University of California, and shall not be used for advertising or product endorsement purposes. 


\title{
Thin film contamination effects on laser-induced damage of fused silica surfaces at $355 \mathrm{~nm}$
}

\author{
F. Y. Génin $\therefore$, A. M. Rubenchick, A. K. Burnham, M. D. Feit, \\ J. Yoshiyama, A. Fornier*, C. Cordillot*, and D. Schirmann*, \\ University of California, Lawrence Livermore National Laboratory, Livermore, California 94550, USA. \\ * CEA-Centre d'Etudes de Limeil-Valenton, 94195 Villeneuve-Saint-Georges - Cédex, France.
}

\begin{abstract}
Fused silica windows were artificially contaminated to estimate the resistance of target chamber debris shields against laser damage during NIF operation. Uniform contamination thin films (1 to $5 \mathrm{~nm}$ thick) were prepared by sputtering various materials $\left(\mathrm{Au}, \mathrm{Al}, \mathrm{Cu}\right.$, and $\left.\mathrm{B}_{4} \mathrm{C}\right)$. The loss of transmission of the samples was first measured. They were then tested at $355 \mathrm{~nm}$ in air with an 8-ns Nd:YAG laser. The damage morphologies were characterized by Nomarski optical microscopy and SEM.

Both theory and experiments showed that metal contamination for films as thin as $1 \mathrm{~nm}$ leads to a substantial loss of transmission. The laser damage resistance dropped very uniformly across the entire surface (e.g. $6 \mathrm{~J} / \mathrm{cm}^{2}$ for $5 \mathrm{~nm}$ of $\mathrm{Cu}$ ). The damage morphology characterization showed that contrary to clean silica, metal coated samples did not produce pits on the surface. $\mathrm{B}_{4} \mathrm{C}$ coated silica, on the other hand, led to a higher density of such damage pits.

A model for light absorption in the thin film was coupled with a simple heat deposition and diffusion model to perform preliminary theoretical estimates of damage thresholds. The estimates of the loss due to light absorption and reflection pointed out significant differences between metals (e.g. $\mathrm{Al}$ and $\mathrm{Au}$ ). The damage threshold predictions were in qualitative agreement with experimental measurements.
\end{abstract}

Key words: UV laser damage, damage morphology, silica, contamination, cleanliness, target chamber, surface damage.

\section{INTRODUCTION}

The development and construction of high fluence lasers for inertial confinement fusion such as the National Ignition Facility (NIF) at Lawrence Livermore National Laboratory (LLNL) or the Laser Mégajoule (LMJ) in France is generating strong interest in the behavior of optical components under a variety of conditions that can lead to damage. It is already a challenge to prevent damage of clean optics under intense laser illumination. ${ }^{1-7}$ For optics subject to contamination and to $355 \mathrm{~nm}$ and x-ray irradiation, the challenge is even higher. ${ }^{8-11}$ In particular, the debris shields (fused silica flats) in the target chamber will be exposed to significant amounts of contamination (see Fig. 1). A preliminary analysis of the source and amount of contamination has cstimated that the target will gencratc about 1 gram of matcrial (c.g. $\mathrm{Au}, \mathrm{Cu}$, stainless steel, $\mathrm{Al}$ ), the target positioner and diagnostics 0.3 gram (stainless steel and $\mathrm{B}_{4} \mathrm{C}$ ), and the beam dump 0.1 gram (stainless steel). In addition, remobilized debris from the first wall could produce 1.4 gram and the silica from damaged and ablated optics $1 \mathrm{~g}$. Table 1 summarizes the estimate of the weight of material and the equivalent thickness that could be deposited onto the debris shields after one NIF shot.

Finally, the refinishing and replacement rates of debris shields will have a major impact on the operating budget of NIF. Estimates have shown that the annual NIF operating cost for debris shields coating, refinishing and/or replacement could run between 4 and 20 times the capital cost for producing the 192 original debris shields. ${ }^{12}$

This article will first present a model describing how light is absorbed and reflected by very thin films on silica. The model will then be coupled with a simple one-dimensional calculation of heat (point source) deposition and diffusion. This thermal model will provide preliminary theoretical estimates of laser damage thresholds. The results of experimental 355-nm laser damage tests and damage morphology characterization

\footnotetext{
$\therefore$ electronic mail: fgenin@llnl.gov
} 
of artificially contaminated fused silica windows will then be described and compared to the theoretical calculations.

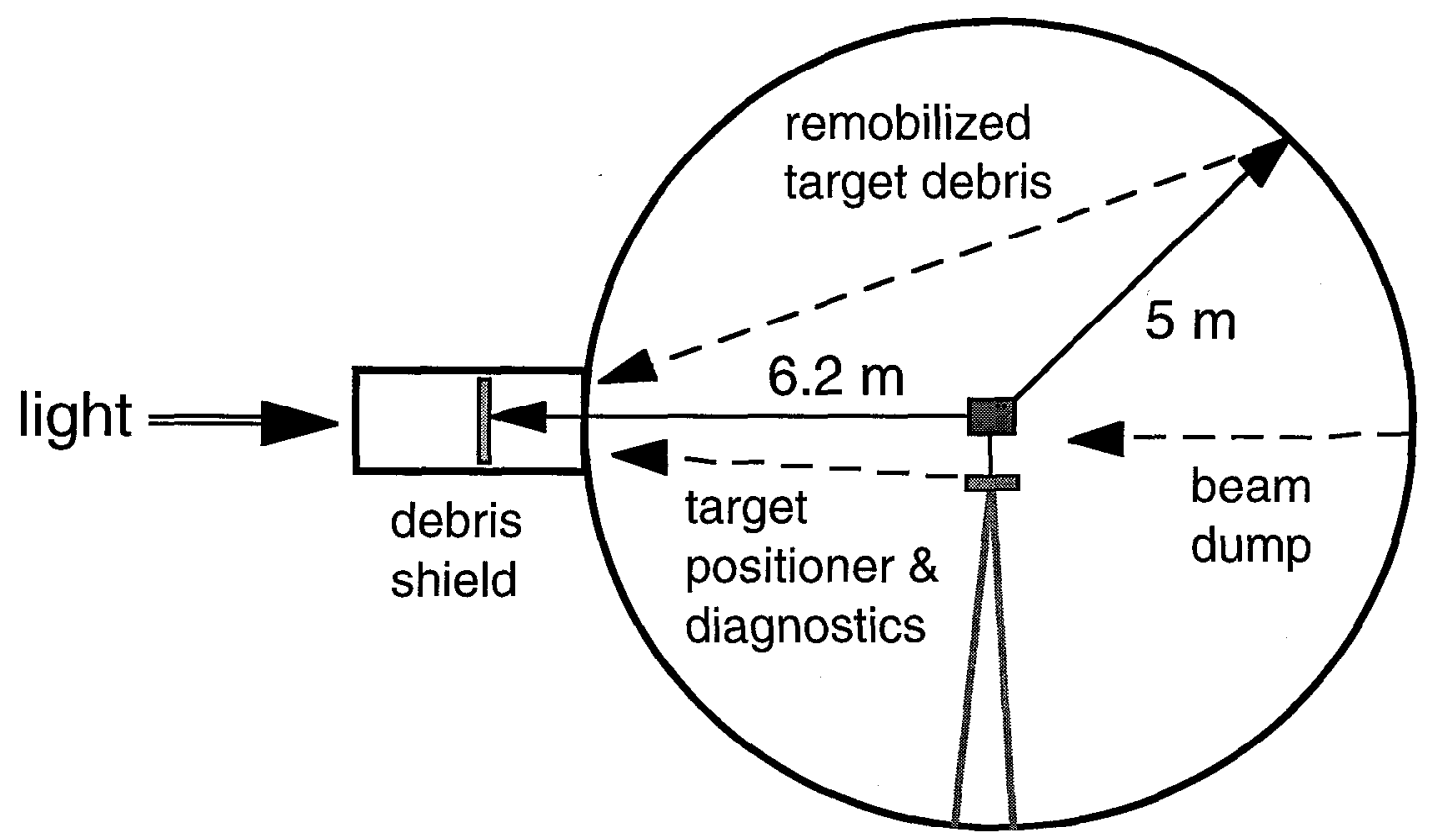

Figure 1: Schematic diagram of the target chamber showing the potential exposure of debris shields to contamination from the Holhraum, the target positioner and diagnostic, the beam dumps and remobilized debris from the first wall.

\begin{tabular}{|c|c|c|c|}
\hline Material & Mass $\left(\mu \mathrm{m} / \mathrm{cm}^{2}\right)$ & Thickness $(\AA)$ & \multirow{7}{*}{$\begin{array}{l}\text { Table 1: Estimated weight of material and } \\
\text { equivalent thickness that could be deposited } \\
\text { onto the debris shields after each NIF shot } \\
\text { assuming the contamination is spread evenly } \\
\text { over } 300 \mathrm{~m}^{2} \text {. }\end{array}$} \\
\hline $\mathrm{Au}$ & 0.09 & 0.5 & \\
\hline $\mathrm{Cu}$ & 0.23 & 2.5 & \\
\hline $\mathrm{Al}$ & 0.05 & 1.8 & \\
\hline $\mathrm{SiO}_{2}$ & 0.23 & 10.0 & \\
\hline $\mathrm{B}_{4} \mathrm{C}$ & 0.09 & 3.6 & \\
\hline stainless steel & 0.14 & 1.7 & \\
\hline
\end{tabular}

In the following, the phrase "laser damage" will often be used. It is necessary to clarify its meaning within the context of this work. We usually classify damage into three categories: benign, massive and catastrophic. Benign damage describes sub-micron-size pits on the surface that are found at the onset of damaging fluences. Massive damage refers to damage that will affect the performance of the optic beyond the tolerance limits of the laser but is stable on subsequent shots at the same fluence. Finally, catastrophic damage (also named massive unstable) refers to the case where the glass begins to crack or be ablated during repetitive illumination. For fused silica irradiated at $355 \mathrm{~nm}$, benign damage turns into catastrophic damage with only a very small increment in fluence (less than $1 \mathrm{~J} / \mathrm{cm}^{2}$ ). In this study, the experimental procedure was tuned to detect the onset of catastrophic damage. Further work is necessary however, to determine whether expected thin film contamination in NIF target chamber will exceed levels that would seriously deteriorate the functionality of the NIF debris shields.

\section{LIGHT ABSORPTION AND REFLECTION IN VERY THIN FILMS}

First, the light absorption in a very thin film is modeled. Consider a transparent silica window coated with a metal film thinner than $50 \mathrm{~nm}$. The absorption and reflection of light through the metal-silica system is well described theoretically. ${ }^{13}$ If the incident beam is normal to the surface, and the exit medium 
is vacuum, the reflection coefficient, (i.e. the ratio between the amplitude of reflected to that of the incident wave), $r$ is given by:

$$
r=\frac{\left(r_{12}+r_{23} e^{2 i \phi}\right)}{\left(1+r_{12} r_{23} e^{2 i \phi}\right)}
$$

where $r_{i k}$ is the reflection coefficient interface between medium $i$ and $k, n_{i}$ is a refractive index of medium i, and indices $1,2,3$ correspond to silica, metal and vacuum;

$$
r_{i k}=\frac{n_{i}-n_{k}}{n_{i}+n_{k}}
$$

For silica, the refractive index $\mathrm{n}$ is about 1.5 and for the metal film, the refractive index $n$ is a complex number. The phase change in the metal film $\Phi=\mathrm{khn}$, where $\mathrm{k}$ is the light wavenumber in vacuum, $\mathrm{h}$-film thickness. Since khn $<<1$, the film transparency (i.e. the ratio of the amplitude of the transmitted to that of the incident wave), $t$ is given by:

$$
t=4 \frac{e^{i \phi} n_{1} n_{2}}{\left(n_{2}+n_{1}\right)\left(n_{2}+n_{3}\right)\left(1+r_{12} r_{23} e^{2 i \phi}\right)}=6 \frac{e^{i \phi} n}{\left(1+r_{12} r_{23} e^{2 i \phi}\right)(n+1)(n+1.5)}
$$

and the absorption, $\mathrm{A}$, is given by:

$$
A=1-|r|^{2}-\frac{n_{3}}{n_{1}}|t|^{2}=1-|r|^{2}-\frac{1}{1.5}|t|^{2}
$$

The complex refractive index $\mathrm{n}$ in the UV is not often available. Furthermore, substantial variations are found in the published literature. These can be expected from differences with bulk data and because the refractive index can be sensitive to the film preparation method. The data reported in Table 2 and used to compare model with experiments should therefore be treated only as indicative.

\begin{tabular}{|c|c|}
\hline Material & Refractive index at $355 \mathrm{~nm}$ \\
\hline $\mathrm{Au}$ & $1.74+1.85 \mathrm{i}$ \\
\hline $\mathrm{Al}$ & $0.38+4.3 \mathrm{i}$ \\
\hline $\mathrm{Cu}$ & $1.31+1.87 \mathrm{i}$ \\
\hline $\mathrm{Ag}$ & $0.2+1.44 \mathrm{i}$ \\
\hline
\end{tabular}

Table 2: Complex refractive index at $355 \mathrm{~nm}$

for gold, aluminum, copper,and silver. ${ }^{14}$

Figure 2 shows the reflection and absorption coefficients as a function of thickness at $355 \mathrm{~nm}$. The calculations are performed for four metals: gold, aluminum, copper, and silver. As anticipated from the values of $\mathbf{n}$ in Table 2, the calculations show that aluminum absorbs and reflects very differently from gold, copper and silver, which behave in a similar fashion. It should be emphasized that if oxidation of the metal occurs, the results can be significantly affected. For example, aluminum quickly forms a transparent surface oxide with a thickness of about $3.5 \mathrm{~nm}$, and a plot of transmittance versus thickness extrapolates to zero at that thickness. 


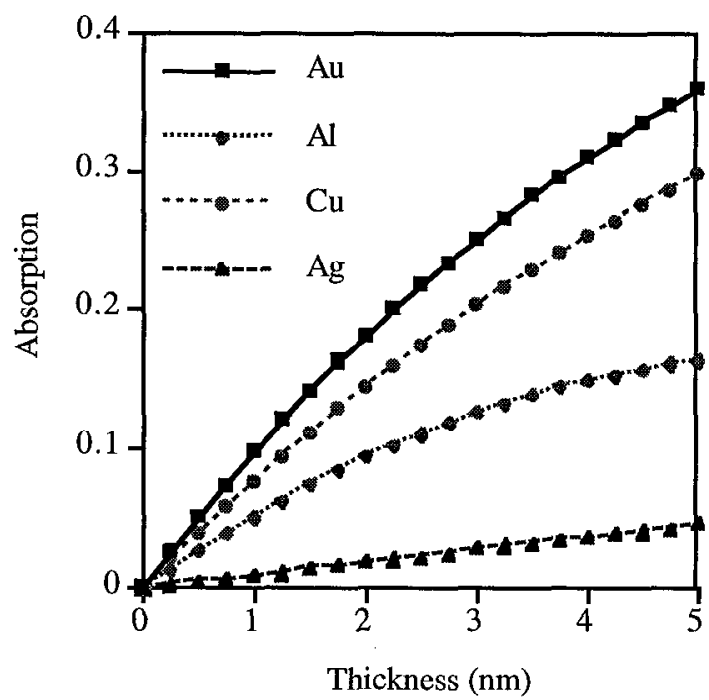

a) Absorption

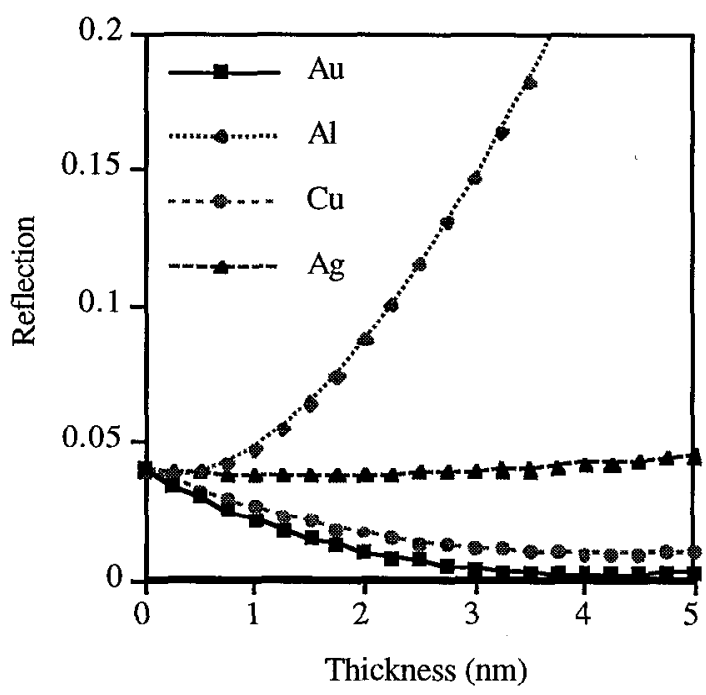

b) Reflection

Figure 2: a) Reflection and b) absorption coefficients as a function of thickness for $\mathrm{Au}, \mathrm{Al}, \mathrm{Cu}$, and $\mathrm{Ag}$ at $355 \mathrm{~nm}$. Note that the scales are different for these two graphs.

\section{ENERGY DEPOSITION AND HEAT DIFFUSION INTO SILICA}

Scveral mechanisms can initiate damage in silica. Film heating can generate thermo-clastic stresses and crack the glass. This effect may be intensified by producing stress gradients if the film is not uniform. The absorbing metal film first heats up the glass. Above a critical temperature (e.g. $1500^{\circ} \mathrm{C}$ ), silica begins to absorb the laser radiation more effectively. The absorption zone propagates upstream with the lasersupported detonation wave. The exploding film can then generate high pressures at the glass-film interface. If the film is not homogeneous, the transversal pressure gradient can crack the surface. Also, UV radiation from the plasma flash may produce F-centers in the glass which can later absorb the energy during subsequent pulses. Noticeable reflection from the film can produce local field intensification via interference with the incident wave stimulating damage initiation. Glass damage can take place if the glass temperature exceeds a critical value at which it is no longer transparent or melting could take place. This critical temperature is assumed to be between $1000^{\circ} \mathrm{C}$ and $2000^{\circ} \mathrm{C}$.

The energy absorbed in the film is the product of the fluence of laser pulse, F, and the absorption coefficient, A. This energy is distributed in a layer thickness, 1 , written as:

$$
l=2 \sqrt{\chi \tau}
$$

where $\chi$ is the thermal diffusivity and $\tau$ is the pulse length. Since the pulse is very short, this layer is very thin and the temperature in the film is very uniform. The heat source can therefore be approximated as a point source. The energy to evaporate the thin metal layer is small compared to that transferred to the glass. The temperature of the glass is therefore given by:

$$
\mathrm{T}=\frac{A F}{\rho c \sqrt{\chi \tau}}=\frac{A F}{\sqrt{\tau}} 10^{5} \mathrm{~K},
$$

where the fluence is expressed in $\mathrm{J} / \mathrm{cm}^{2}$ and the pulse duration in nanoseconds. Equation (6) can only give an approximate estimate of the glass temperature. However, an absorption level of only $1 \%$ with a 3-ns, 5 $\mathrm{J} / \mathrm{cm}^{2}$ pulse can heat the surface of a silica layer to 2,900K (above the critical temperature of enhanced absorption and above the glass transition temperature). 


\section{EXPERIMENTAL RESULTS}

\subsection{Experimental procedure:}

Laser damage tests were carried out at $355 \mathrm{~nm}$ using an 8.4-ns Nd:YAG laser in S-polarization at $5^{\circ}$ and $20^{\circ}$ incidence angle using a $1 / 1$ (single shot) and $\mathrm{R} / 1$ (ramping test) procedure. The laser was focused to provide a Gaussian beam with a diameter of $1.2 \mathrm{~mm}$ at $1 / \mathrm{e}^{2}$ peak intensity. Damage was detected by monitoring the scattering of a HeNe laser focused on the output surface of the tested site; a site was declared damaged when light scattering reached a given threshold. In this study, the damage detected by the HeNe was catastrophic. The R/1 laser damage maps were obtained to measure the average LIDT, the standard deviation, the lowest and higher LIDT. While the average damage threshold is a good measure of the overall quality of an optic, the standard deviation provides information on the uniformity of the material and process. ${ }^{15,16}$ Finally, the lowest threshold to failure is an important engineering parameter for the laser since it will determine the damage threshold and the functionality of large-area optics. Damage for the $1 / 1$ tests were characterized by Nomarski optical microscopy and SEM.

A set of Corning UV grade fused silica blanks $11 \mathrm{~mm}$ thick and $50 \mathrm{~mm}$ in diameter were polished using a medium and a high LIDT polishing process. The samples were then cleaned at LLNL using the NIF standard cleaning procedure. A set of samples was contaminated by sputtering material $(\mathrm{Al}, \mathrm{Au}, \mathrm{Cu}$, and $\left.\mathrm{B}_{4} \mathrm{C}\right)$ onto the surface. The tests were performed with the contamination film on the output surface.

\subsection{Damage threshold measurements:}

The $\mathrm{R} / 1$ damage threshold measurements were performed on two polished bare fused silica windows and on fused silica contaminated with $5 \mathrm{~nm}$ of $\mathrm{Cu}$. Twenty sites were measured for each sample. The average LIDT for the two polished silica samples were 20.1 and $27.6 \mathrm{~J} / \mathrm{cm}^{2}$, respectively. The contaminated samples damaged at 10.5 and $11.0 \mathrm{~J} / \mathrm{cm}^{2}$, respectively. The typical standard deviation for clean silica and for the contaminaled silica was about $3.2 \mathrm{~J} / \mathrm{cm}^{2}$, and $0.4 \mathrm{~J} / \mathrm{cm}^{2}$.

For all other samples, the presence of a contamination layer also led to very uniform damage behavior. Low fluences shots on a contaminated surface systematically ignited plasmas. Although it was not quantified, all tested samples (even with the $1 \mathrm{~nm}$ deposits) showed a substantial degradation in damage resistance.

\subsection{Damage morphology characterization}

The damage morphology characterization of the samples showed that the surface of a clean silica after irradiation is covered with ellipsoidal micro-pits. ${ }^{17}$ The sample with a higher LIDT had a much lower micropit (i.c. damage precursor) density (sec Fig. 3). ${ }^{16}$

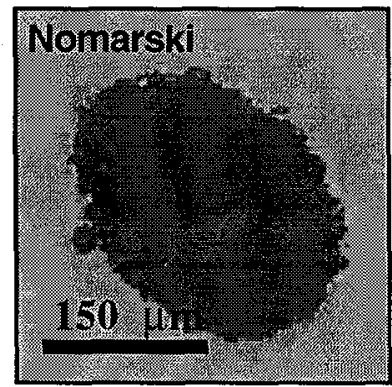

a) medium damage threshold polish

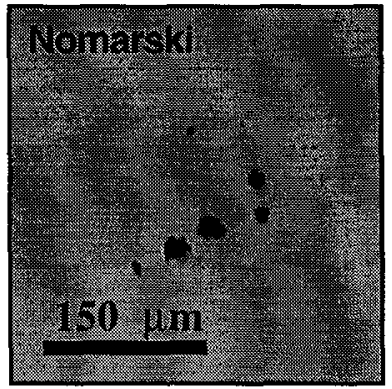

b) higher damage threshold polish

Figure 3: Nomarski optical micrographs of output damage on a clean surface after a single pulse in "P" polarization in air at $355 \mathrm{~nm}$ at about $30 \mathrm{~J} / \mathrm{cm}^{2}$; a) medium damage threshold surface with a high density of damage initiators and $b$ ) higher damage threshold surface with fewer cracks. 
The bare surface, the $\mathrm{Cu}$ and $\mathrm{B}_{4} \mathrm{C}$ film contamination samples led to different damage morphologies (see Fig. 4). At the onset of damage, a medium density of micron-size pits was found after irradiating the clean silica surface. Micro-scratches were not usually revealed. A higher pit density was detected for the $\mathrm{B}_{4} \mathrm{C}$ and fine scratches were outlined. The surface damage pits were smaller than for clean surfaces after damage. Finally, no pits were found on metal contaminated surfaces $(\mathrm{Cu}, \mathrm{Au}$, and $\mathrm{Al}$ ); however, scratches were also outlined. The areas damaged at higher fluence on metal contaminated surface showed strong evidence of surtace melting.

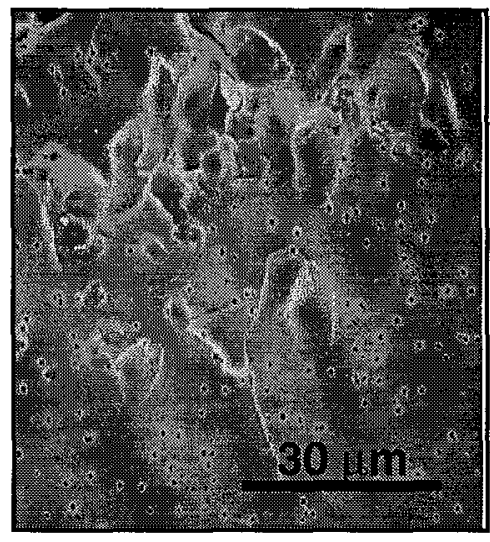

a) bare surface

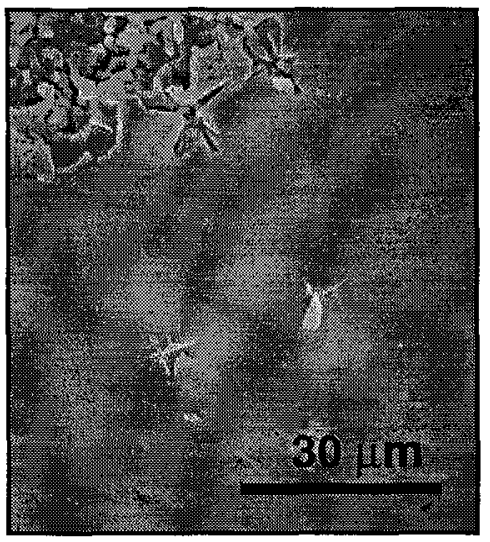

b) $5 \mathrm{~nm} \mathrm{Cu}$

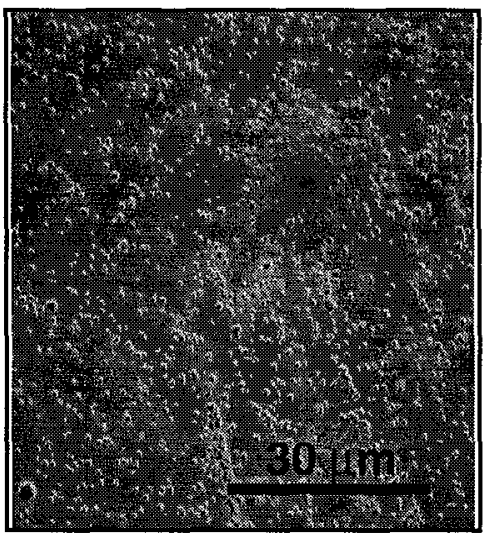

c) $2 \mathrm{~nm} \mathrm{~B}{ }_{4} \mathrm{C}$

Figure 4: SEM micrographs of output surface damage after a single 8.4-ns pulse in "P" polarization in air at $355 \mathrm{~nm}$ : a) clean surface at $20 \mathrm{~J} / \mathrm{cm}^{2}$, b) surface coated with $5 \mathrm{~nm}$ of $\mathrm{Cu}$ at $20 \mathrm{~J} / \mathrm{cm}^{2}$, and c) surface coated with $5 \mathrm{~nm}$ of $\mathrm{B}_{4} \mathrm{C}$ at $25 \mathrm{~J} / \mathrm{cm}^{2}$.

\section{CONCLUSION}

Fused silica windows were artificially contaminated with various materials $\left(\mathrm{Au}, \mathrm{Al}, \mathrm{Cu}\right.$, and $\left.\mathrm{B}_{4} \mathrm{C}\right)$. $\mathrm{A}$ substantial loss of transmission (greater than 1\%) was measured for metal contamination films as thin as 1 $\mathrm{nm}$. The damage tests at $355 \mathrm{~nm}$ in air with an 8-ns Nd:YAG laser showed that the damage resistance of contaminated fused silica drops very uniformly across the entire surface.

Theoretical calculations of absorption and reflection due to the presence of contamination confirmed that very thin layers could greatly reduce transmission and initiate damage at the surface. For example, a gold film, $1 \mathrm{~nm}$ thick, can absorb as much as $10 \%$ of the incident energy. Substantial differences between metals (e.g. gold and aluminum) were predicted.

A simple heat absorption and diffusion model showed that a $3-\mathrm{ns}, 5 \mathrm{~J} / \mathrm{cm}^{2}$ laser pulse could initiate damage if contamination was to absorb only one percent of the energy. These predictions were in qualitative agreement with the experimental measurements.

Finally, the damage morphology characterization showed that contrary to clean fused silica, metal coated samples did not produce micro-pits on the surface. $\mathrm{B}_{4} \mathrm{C}$ coated silica, on the other hand, led to a higher density of such damage pits.

To summarize, these results clearly confirm that at high fluence, trace level contamination is potentially very harmful to the integrity of transmissive fused silica optics. Further evaluation of contaminationinitiated laser damage is necessary to better predict the lifetime of NIF final optics assembly.

\section{ACKNOWLEDGMENTS}

This work was performed under the auspices of the U.S. Department of Energy by Lawrence Livermore National Laboratory under Contract W-7405-Eng-48, by the Mégajoule Project (CSL-CEA, Department Limeil-Valenton), and the French Ministry of Defence. Many thanks are expressed to Guy Robitaille for preparing clean samples, Mark McKernan for depositing the metal contamination films on the surface and Collin Battersby for performing automated damage tests the $\mathrm{Cu}$ contaminated samples. 


\section{REFERENCES}

1. N. L. Boling, G. Dubé, M. D. Crisp, "Laser surface damage studies on several glasses", in Laser Induced Damage in Optical Materials, NBS-SP 387, 69 (1973).

2. N. L. Boling, J. A. Ringlien, and G. Dubé, "Q-switched laser induced surface damage at $1 \mu \mathrm{m}$ ", in Laser Induced Damage in Optical Materials, NBS-SP 414, 119 (1974).

3. R. A. House, J. R. Bettis, and A. H. Guenther, "Subsurface structure and laser damage threshold", IEEE

J. of Quant. Electronics QE-13, 363 (1977).

4. H. Vora, R. H. Anderson, and R. J. Stokes, "Surface finishing using soft abrasives", in Laser Induced Damage in Optical Materials, NBS-SP 638, 262 (1981).

5. H. Vora, W. H. Lowdermilk, and J. E. Swain, "Effect of surface finishing on the damage threshold of fused silica at $1.06 \mu \mathrm{m}$ ", in Laser Induced Damage in Optical Materials, NBS-SP 669, 146 (1982).

6. Y. Namba, "Float polishing and defects of fused silica", in Laser Induced Damage in Optical Materials, NBS-SP 669, 138 (1982).

7. Y. Namba, M. Saeki, M. Shiokawa, K. Yoshida, et al., "Ultraviolet-laser-damage threshold of optical glasses finished by various methods", in Summaries of Papers Presented at the Conference on Lasers and Electro-Optics, IEEE Cat. No. 95CH35800, 410 (1995).

8. F. Y. Génin, K. Michlitsch, J. Furr, M. R. Kozlowski, and P. Krulevitch, "Laser-induced damage of fused silica at 355 and $1064 \mathrm{~nm}$ initiated by aluminum contamination particles on the surface", in Laserinduced damage in optical materials, SPIE Vol. 2966, 126 (1996).

9. M. D. Feit, A. M. Rubenchik, D. R. Faux, R. A. Riddle, A. B. Shapiro, D. C. Eder, B. M. Penetrante, D. Milam, F. Y. Génin, and M. R. Kozlowski, "Modeling of laser damage initiated by surface contamination", in Laser-induced damage in optical materials, SPIE Vol. 2966, 417 (1996).

10. J. Dijon, P. Garrec, N. Kaiser, and U.B. Schallenberg, "Influence of substrate cleaning on LIDT of 355 nm HR coatings", in Laser-induced damage in optical materials, SPIE Vol. 2966, 178 (1996).

11. D. J. Gallant, M. Law, and B. Pond, "Effect of cleaning on the optical absorption of calcium fluoride and fused silica at 351 nm", in Laser-induced damage in optical materials, NIST SP 752, 159 (1986).

12. P. Whitman, private communication.

13. M. Born, E. Wolf, in Principles of oplics, Permagmon Press, Oxford, 1959.

14. E. D. Palik, Handbook of optical constant of solids, Academic Press, Orlando, 1985.

15. J. Hue, F. Y. Génin, S. M. Maricle, and M. R. Kozlowski, "Toward predicting the laser damage threshold of large-area optics", in Laser-induced damage in optical materials, SPIE Vol. 2966, 451 (1996).

16. F. Y. Génin, L. M. Sheehan, J. Yoshiyama, J. Dijon, and P. Garrec, "Statistical study of UV-laserinduced failure of fused silica", Laser-induced damage in optical materials, SPIE Vol. 3244, 155 (1997).

17. J. Yoshiyama, F. Y. Génin, A. Salleo, I. M. Thomas, M. R. Kozlowski, L. M. Shechan, I. D. Hutcheon and D. W. Camp, "Effects of polishing, etching, cleaving and water leaching on the UV laser damage of fuscd silica", Laser-induced damage in optical materials, SPIE Vol. 3244, 331 (1997). 